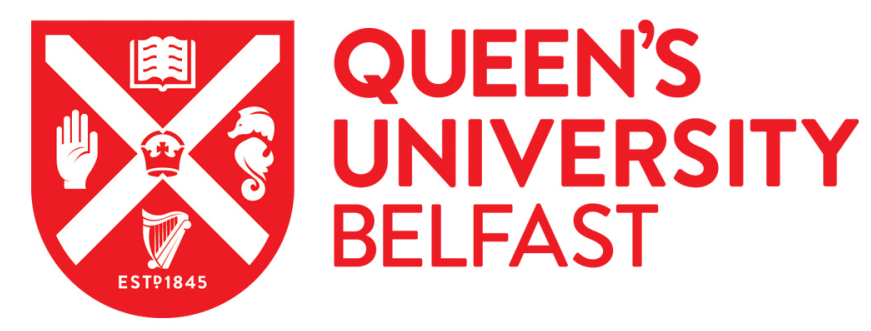

\title{
Detection Limits of Organic Compounds Achievable with Intense, Short-Pulse Lasers
}

Miles, J., De Camillis, S., Alexander, G., Hamilton, K., Kelly, T. J., Costello, J. T., Zepf, M., Williams, I. D., \& Greenwood, J. B. (2015). Detection Limits of Organic Compounds Achievable with Intense, Short-Pulse Lasers. Analyst, 140(12), 4270-4276. https://doi.org/10.1039/c5an00529a

\section{Published in:}

Analyst

\section{Document Version:}

Peer reviewed version

Queen's University Belfast - Research Portal:

Link to publication record in Queen's University Belfast Research Portal

Publisher rights

(c) 2015 Royal Society of Chemistry

\section{General rights}

Copyright for the publications made accessible via the Queen's University Belfast Research Portal is retained by the author(s) and / or other copyright owners and it is a condition of accessing these publications that users recognise and abide by the legal requirements associated with these rights.

Take down policy

The Research Portal is Queen's institutional repository that provides access to Queen's research output. Every effort has been made to ensure that content in the Research Portal does not infringe any person's rights, or applicable UK laws. If you discover content in the Research Portal that you believe breaches copyright or violates any law, please contact openaccess@qub.ac.uk. 


\title{
ARTICLE
}

Cite this: DOI: $10.1039 / \times 0 x x 00000 x$

\section{Detection Limits of Organic Compounds Achievable with Intense, Short-Pulse Lasers}

\author{
Jordan Miles ${ }^{\mathrm{a}}$, Simone De Camillis ${ }^{\mathrm{a}}$, Grace Alexander ${ }^{\mathrm{a}}$, Kathryn Hamilton ${ }^{\mathrm{a}}$, \\ Thomas J. Kelly ${ }^{\mathrm{b}}$, John T. Costello ${ }^{\mathrm{b}}$, Matthew Zepf ${ }^{\mathrm{a}}$, Ian D. Williams ${ }^{\mathrm{a}}$, and Jason \\ B. Greenwood*a
}

Received 00th January 2012, Accepted 00th January 2012

DOI: $10.1039 / \times 0 \times x 00000 x$

Many organic molecules have strong absorption bands which can be accessed by ultraviolet short pulse lasers to produce efficient ionization. This resonant multiphoton ionization scheme has already been exploited as an ionization source in time-of-flight mass spectrometers used for environmental trace analysis. In the present work we quantify the ultimate potential of this technique by measuring absolute ion yields produced from the interaction of $267 \mathrm{~nm}$ femtosecond laser pulses with the organic molecules indole and toluene, and gases $\mathrm{Xe}, \mathrm{N}_{2}$ and $\mathrm{O}_{2}$. Using multiphoton ionization cross sections extracted from these results, we show that the laser pulse parameters required for real-time detection of aromatic molecules at concentrations of one part per trillion in air and a limit of detection of a few attomoles are achievable with presently available commercial laser systems. The potential applications for the analysis of human breath, blood and tissue samples are discussed.

\section{Introduction}

The potential for using resonantly enhanced multiphoton ionization (REMPI) to detect trace amounts of organic molecules has been recognized for at least 35 years ${ }^{1,2,3}$. By using ultraviolet laser pulses which are resonant with allowed transitions in the molecules, extremely efficient, soft ionization is possible allowing identification in a mass spectrometer with a sensitivity which theoretically approaches the single molecule limit.

To date the potential of this technique has mainly been investigated using low repetition rate nanosecond lasers as the ionization source. A straightforward way to efficiently ionize aromatic molecules is to use the fourth harmonic of a Nd:YAG laser $(266 \mathrm{~nm})$ for resonant ionization via a $1+1$ photon absorption scheme. A wider range of molecules can be accessed using shorter wavelengths (e.g. fifth harmonic) or an optical parametric oscillator (OPO). The wavelength tunability of an OPO can also enhance the signal and species selectivity if specific peaks in the absorption spectrum can be picked out. This can be further optimized if the gas is cooled in a jet expansion to limit transitions from excited vibrational and rotational levels of the ground electronic state ${ }^{4}$. This JetREMPI scheme is very useful in complex samples as it also allows isobars and isomers to be clearly identified, for example xylenes $^{5,6,7}$ and xylenols ${ }^{8}$. The pulsed nature of these sources makes them ideally suited for integration into time-of-flight (ToF) mass spectrometers.
Since the typical laser intensities are well below that required for non-resonant ionization of background gases, very high sensitivities can be obtained from direct analysis of gas samples without pre-concentration. As a result REMPI has been employed in a number of environmental monitoring studies, particularly in the study of the chemical composition of the exhaust gases from combustion processes such as waste incineration $^{6,7,9,10}$, and engines or generators ${ }^{4,5,11}$ (see Streibel and Zimmermnn for a recent review ${ }^{12}$ ). These studies have demonstrated that an extensive range of volatile organic compounds (VOCs) such as simple aromatics $4,6,13,5,11,10$ aldehydes ${ }^{4,14}$ amines ${ }^{15}$, polychlorinated biphenyls $(\mathrm{PCBs})^{14,16,17}$, poly-aromatic hydrocarbons (PAHs) $)^{5,9,11,10}$ and dioxins ${ }^{18}$ can be detected at parts per trillion (ppt) concentration levels.

This direct sampling, high sensitivity approach could also make Jet-REMPI-ToF valuable for characterizing human breath, which is being widely investigated and promoted as a non-invasive diagnostic for a range of diseases, particularly cancer. Short et al. ${ }^{19}$ have demonstrated that wavelength selective resonant ionization enables the nitric oxide concentration of human breath to be monitored in real time with ppb sensitivity. Oser et al. ${ }^{20}$ have also detected a range of aromatic molecules which are potential disease biomarkers with sensitivities nearly two orders of magnitude greater than that achievable with a conventional gas chromatograph-mass spectrometer (GC-MS). Given these promising preliminary results it is surprising that many more studies have not been 
forthcoming. This might be attributed to a reluctance to utilize lasers which are costly, bulky and require operational expertise in a medical setting.

For solid and liquid samples, ns-REMPI has also been used as an ionization source in GC-MS-ToF instruments. For instance it was shown to be superior to electron impact ionization for identifying PAHs in river water samples since there was less molecular fragmentation and better selectivity $^{21,22}$. Alternatively the third harmonic of Ti:Sapphire femtosecond lasers $(267 \mathrm{~nm})$ has also been used since it gives higher ionization efficiency for molecules with intermediate excited states possessing short lifetimes. For example, excited singlet states of dioxins undergo rapid inter-system crossings to lower lying triplet levels, but using a fs laser allows sample sizes in the femtogram range to be measured ${ }^{23,24,25}$.

As the size of the molecule increases, more pathways for redistribution of the excitation energy become available. As a result the ionization efficiency is expected to drop for ns lasers and there is an increased degree of fragmentation. This is due to a transition from a ladder climbing process to a ladder switching one where evolution of intermediate excited states opens up many more dissociation channels, thus emphasizing the advantage in using femtosecond pulses for more complex molecules. This was demonstrated in a study comparing the spectra and ionization yields of peptides by fs and ns lasers operating at $267 \mathrm{~nm}^{26}$. For compounds lacking conjugated double bonds, absorption bands are deeper in the UV. As a result using the fourth $(200 \mathrm{~nm})$ rather than the third harmonic of a Ti:Sapphire laser was found to enhance the limit of detection for a large number of pesticides by up to two orders of magnitude ${ }^{27}$.

Non-resonant ionization using femtosecond lasers has also been considered for analysis of organic compounds due to the high ionization efficiency and low molecular fragmentation ${ }^{28,29,30,31}$. In the tunneling ionization regime there is a strong dependence on the ionization potential which favors ionization of the organic molecules compared with the main gases found in air. However, it is well established that ionization rates for most organic molecules are suppressed compared to atoms with similar ionization potentials ${ }^{32}$. This depends on the nature of the electronic orbital being ionized which can lead to destructive interference in the outgoing wavepackets which suppress the ionization ${ }^{33,34,35}$. Therefore, fs lasers which are non-resonant are unlikely to achieve the highly selective ionization required to detect organic molecules at very low concentrations, but could be used in cases where very high efficiency is required, e.g. post-ionization in secondary ion mass spectrometry ${ }^{36}$.

Despite the fact that resonant and non-resonant multiphoton ionization offers superior efficiency, lower molecular fragmentation, and higher selectivity than other ionization sources, applications described above have been relatively limited to date. This is mainly due to the cost and expertise associated with using the high peak power lasers required for ionization. However, short pulse laser technology has advanced beyond recognition since REMPI analysis was first proposed.
In recent years there have been further dramatic developments in picosecond and femtosecond solid state and fibre lasers based on erbium and ytterbium doped materials. The very high quantum efficiencies of these compounds and the fact that they can be pumped with light emitting diodes rather than separate lasers means that these compact, turnkey and robust devices are now widely used in material processing, telecommunications, medicine and in many research applications. As a result the footprint and price of these lasers has concomitantly been falling rapidly, opening up the possibility of greater exploitation in trace chemical analysis.

In this paper we assess the merits of using commercially available high average power, short pulse lasers for detecting aromatic compounds at ultralow concentrations. We gauge the relative merits of laser parameters such as repetition rate, pulse energy, beam size, and pulse length on the ionization efficiency of analyte molecules and background gases. To compare the relative ionization efficiencies of exemplar aromatic molecules to other gases, we have measured absolute ion yields using a simple ToF device described in Section II. In Section III we formulate the ion yields expected for the multi-photon ionization and in Section IV present the experimental ion yields produced from $267 \mathrm{~nm}$, femtosecond pulse interactions with indole, toluene, $\mathrm{Xe}, \mathrm{N}_{2}$ and $\mathrm{O}_{2}$ for a range of intensities. Although we use the organic molecules primarily as exemplars, their trace detection is of particular interest since indole has been demonstrated as a marker for stress in humans ${ }^{37}$ and elevated levels of toluene in human breath have been correlated with lung cancer and smoking ${ }^{38,39}$. From these results the laser parameters required to detect $1 \mathrm{ppt}$ concentrations in air are estimated in Section V. Section VI summarizes these results and also considers the ideal laser characteristics for ultra-high sensitivity detection, the technological developments which might enhance this further, and the potential applications in medicine and trace analysis.

\section{Experimental Setup}

The ultraviolet laser pulses used to ionize various gases were produced from the third harmonic conversion of a Coherent Inc. Libra titanium:sapphire laser operating at $1 \mathrm{kHz}$. The resulting pulses had a central wavelength of $267 \mathrm{~nm}$ with a bandwidth of $1 \mathrm{~nm}$, pulse energies of $50 \mu \mathrm{J}$, and $130 \mathrm{fs}$ duration (measured from cross correlation with the fundamental). To obtain ion yields as a function of the peak intensity, pulses were attenuated by rotating a half waveplate placed in front of a Glan-Laser polarizer. The pulses were focused by a spherical lens $(\mathrm{f}=0.175 \mathrm{~m})$ into the extraction region of a small, home built ToF mass spectrometer.

The interaction region of the ToF consisted of a repeller plate held at a potential of $+5 \mathrm{kV}$ with a $5 \mathrm{~mm}$ gap to an extraction plate at $+4.7 \mathrm{kV}$. A glass cylinder with a resistive inner coating and $35 \mathrm{~mm}$ length was used to generate a uniform electric field between the extraction plate and a grounded flight tube of $280 \mathrm{~mm}$ length. To measure the absolute ion yield per laser shot, a flat stainless steel disc was connected to a low noise charge sensitive amplifier (Amptek CoolFET) which had 
previously been calibrated absolutely ${ }^{40}$. As a result of the image charge produced by the ions as they approach this plate, the time resolution of this detector was modest but sufficient to separate the ions being studied. The acceptance aperture to the flight tube of diameter $L=10 \mathrm{~mm}$ was much greater than the Rayleigh length $z_{0}$ of the focused laser beam. To obtain single ionization yields for molecular species, dissociative ionization was included by summing the contributions from fragments as well as the parent ions.

A constant target density was achieved by flooding the chamber with the target gas. The pressure was monitored with an ion gauge and the relative densities of each gas were obtained by correcting for the ion gauge sensitivity. For $\mathrm{O}_{2}, \mathrm{~N}_{2}$ and $\mathrm{Xe}$ standard correction factors were used, while factors for toluene and indole were derived from the ratio of their electron impact ionization cross sections (at $100 \mathrm{eV}$ ) to that of $\mathrm{N}_{2}{ }^{41,42}$.

\section{Ion Yield Simulations}

For resonantly enhanced $1+1$ ionization with photons of energy $\hbar \omega$, if the rate of excitation from the ground to excited state is $\Gamma_{1}(I)$ and the rate of ionization from the excited state to the continuum is $\Gamma_{2}(I)$ where $I$ is the laser intensity, then the probability of ionization $P_{1+1}$ after a time $t$ is (see Supporting Information)

$$
P_{1+1}=1-\frac{\Gamma_{2} \Gamma_{1}}{\Gamma_{2}-\Gamma_{1}}\left[\frac{1}{\Gamma_{1}} \exp \left(-\Gamma_{1} t\right)-\frac{1}{\Gamma_{2}} \exp \left(-\Gamma_{2} t\right)\right]
$$

Assuming the laser has a rectangular temporal profile of length $\tau$, and the intensity is sufficiently low so that $P \ll 1$, the ionization probability in terms of the respective cross sections $\sigma$ is

$$
P_{1+1}(I)=\frac{1}{2} \sigma_{1} \sigma_{2}\left(\frac{I}{\hbar \omega}\right)^{2} \tau^{2}
$$

This equation assumes that the lifetime of the excited state is much longer than the laser pulse length and that its evolution during the pulse does not influence the value of $\sigma_{2}$. Depending on the strength of the excitation, $\sigma_{1}$ could have values in the range $10^{-16}-10^{-20} \mathrm{~cm}^{2}$. Absolute values for a number of volatile organic compounds in the gas phase are available in the literature $^{43,44,45,46,47}$ or can be estimated from molar absorptivities $\epsilon$ via the following conversion

$$
\sigma_{1}\left(\mathrm{~cm}^{2}\right)=3.82 \times 10^{-21} \epsilon\left(\mathrm{l} \mathrm{mol}^{-1} \mathrm{~cm}^{-1}\right)
$$

Ionization cross sections are only known in a few cases ${ }^{3}$, but are generally of the order of $10^{-17} \mathrm{~cm}^{2}$ and are not expected to change dramatically with wavelength or the rovibrational state of the excited level.

For the case of non-resonant ionization via $N$ photon absorption, the ionization probability is

$$
P_{N}(I)=1-\exp \left(-\sigma_{N}\left(\frac{I}{\hbar \omega}\right)^{N} t\right)
$$

where $\sigma_{N}$ is the $N$ photon ionization cross section (units $\left.\mathrm{cm}^{2 N} \mathrm{~S}^{N-1}\right)$.

Values for $\sigma_{N}$ are rarely known, but the cross section for 3 photon ionization of xenon at a wavelength of $266 \mathrm{~nm}$ has been calculated by Kulander et al. ${ }^{48}$ to be $2.5 \times 10^{-82} \mathrm{~cm}^{6} \mathrm{~s}^{2}$, while McGuire et al. ${ }^{49}$ obtained a value of $5 \times 10^{-82} \mathrm{~cm}^{6} \mathrm{~s}^{2}$. In order to estimate ionization cross sections from our experimental ion yields and to predict ion yields from hypothetical gas analysis scenarios, we consider theoretical ion yields from the interaction of the laser beam with a gas target of constant number density $n$. For a tightly focused beam with a gaussian spatial profile and Rayleigh length $z_{0} \ll L$, the total ion yield $Y$ from a pulse of peak intensity $I_{0}$ is obtained by integrating the ionization probability over the focal volume (see SI)

$$
Y\left(I_{0}\right)=\frac{n V_{0}}{3} \int_{I_{\min }}^{I_{0}} \frac{P(I)}{I}\left(\frac{I_{0}}{I}-1\right)^{1 / 2}\left(\frac{I_{0}}{I}+2\right) d I
$$

For a given ionization probability function $P(I)$ (eqn. 1 or 4), this can be numerically integrated for different peak intensities. As the ionization probability approaches 1 , the ion yield keeps increasing due to the increase in iso-intensity volumes which scale as $I^{3 / 2}$ (see SI).

For the other extreme where the laser beam area is constant over an interaction length $L$ (e.g. an unfocussed beam) and assuming it has a full width half maximum diameter of $D$, pulse length $\tau$, and pulse energy $E$, the integrated ion yield $Y_{N=3}$ from this interaction is determined to be (see SI)

$$
Y_{3}=\frac{16(\ln 2)^{2} L n \sigma_{3}}{3 \pi^{2}(\hbar \omega)^{3} D^{4}} \frac{E^{3}}{\tau^{2}}
$$

By similar analysis the yield from resonant $1+1$ ionization is

$$
Y_{1+1}=\frac{(\ln 2) L n \sigma_{1} \sigma_{2}}{(\hbar \omega)^{2} \pi D^{2}} E^{2}
$$

\section{Results}

The $\mathrm{Xe}^{+}$ion yield generated per laser pulse at the focus of the beam, normalized to an absolute gas pressure of $10^{-7} \mathrm{mbar}$, as a function of peak intensity $I_{0}$ is shown in Figure 1(a). Calibration of the intensity scale was obtained by using the cross section of $2.5 \times 10^{-82} \mathrm{~cm}^{6} \mathrm{~s}^{2}$ calculated by Kulander et al. $^{48}$ and fitting eqn. 5 to the experimental ion yield. To extend the measurements to lower intensities $\left(\sim 10^{12} \mathrm{Wcm}^{-2}\right)$, data was also acquired with the laser focus shifted $18 \mathrm{~mm}$ off the ToF axis. These points were corrected for the increased interaction volume and included on Figure 1(a). Trend lines are also plotted which confirm the expected $I^{3 / 2}$ and $I^{3}$ dependencies for $\mathrm{Xe}$ well above and below the saturation intensity respectively.

The yields for $\mathrm{N}_{2}$ and $\mathrm{O}_{2}$ are also shown in Figure 1(a) having been normalized to the same target density as Xe. Similar trends are found for both but with lower yield and higher saturation intensities compared to Xe. The fact that the yield of ions from $\mathrm{N}_{2}$ follows an $I^{3}$ trend at low intensities is surprising given that four photons are required for ionization. This indicates the presence of strong resonances around $14 \mathrm{eV}$ above the $\mathrm{N}_{2}$ ground state ${ }^{50}$. By fitting eqn. 5 to the data, three photon cross sections of $1.8 \times 10^{-83} \mathrm{~cm}^{6} \mathrm{~s}^{2}$ and $3.5 \times$ $10^{-84} \mathrm{~cm}^{6} \mathrm{~s}^{2}$ for $\mathrm{O}_{2}$ and $\mathrm{N}_{2}$ were derived with an uncertainty of $40 \%$.

As indole and toluene are considerably easier to ionize, the same off focus interaction geometry was used to obtain ion yields around the saturation intensity. These results are shown in Figure 1(b) along with yields for much lower intensities obtained using an unfocussed beam (which was again corrected to account for the different interaction geometry). These results follow the expected intensity dependencies of $I^{3 / 2}$ and $I^{2}$ above and below saturation intensities of $2.0 \times 10^{11} \mathrm{Wcm}^{-2}$ 
and $4.5 \times 10^{11} \mathrm{Wcm}^{-2}$ for indole and toluene respectively. The excitation cross section for toluene has been measured previously in the gas phase ${ }^{51}$, while the value for indole can be derived from its molar absorptivity in solution ${ }^{52}$. The $0-0$ transition in toluene is at $272 \mathrm{~nm}$ while at $267 \mathrm{~nm}$ absorption is strong due to a 0-1 transition corresponding to an out of plane $\mathrm{C}-\mathrm{H}$ bending mode. For indole, $0-0$ transitions for the ${ }^{1} \mathrm{~L}_{\mathrm{b}}$ and ${ }^{1} \mathrm{~L}_{\mathrm{a}}$ states are at 285 and $274 \mathrm{~nm}$ respectively so a range of vibrational modes are excited at $267 \mathrm{~nm}^{53}$. As our laser has a bandwidth of $1 \mathrm{~nm}$, we use an average over the laser wavelength range to derive the excitation cross sections presented in table 1 . Using these values, estimates for the ionization cross sections which fit the experimental data are also presented in table 1 .
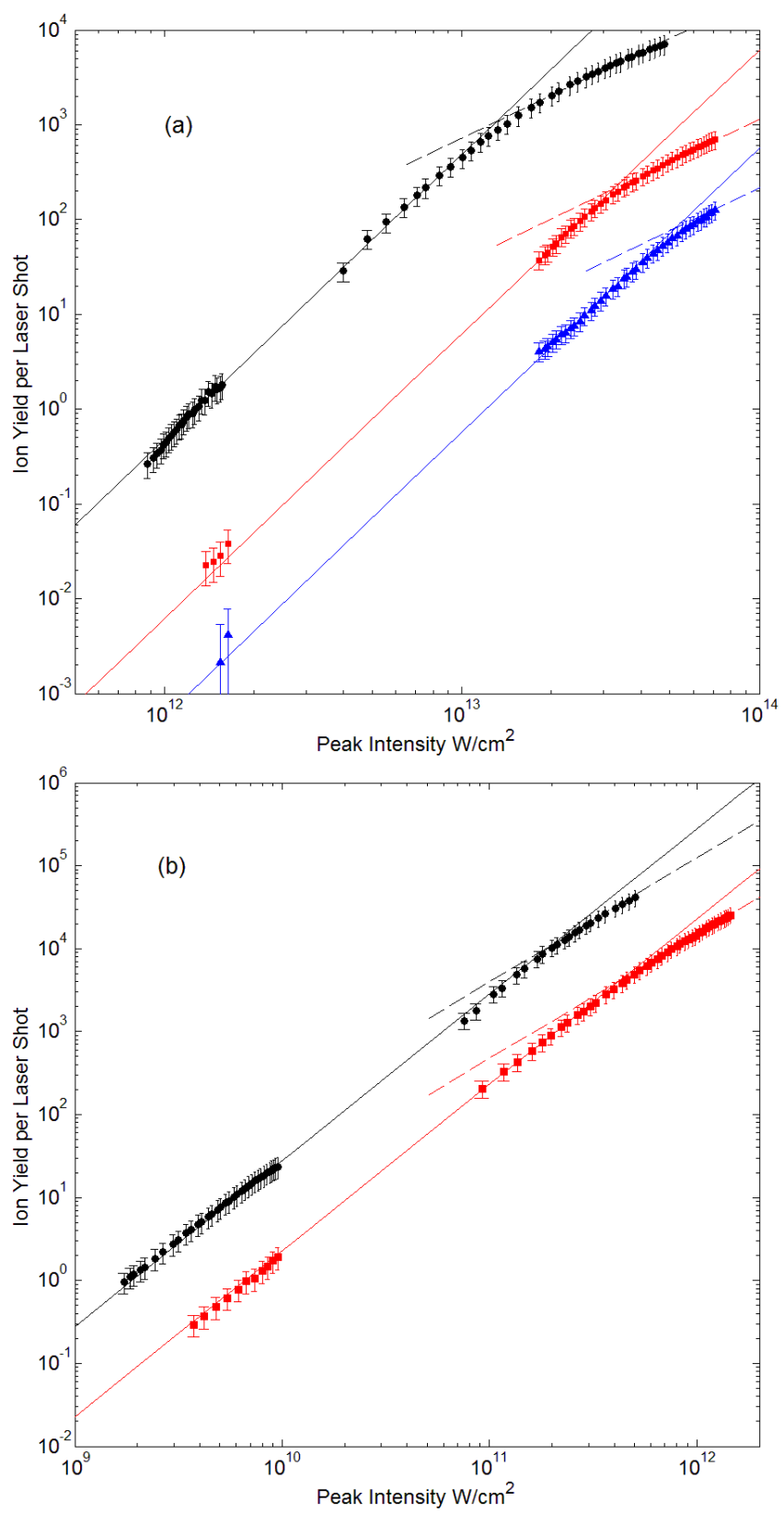

Figure 1. Ion yield per laser shot as a function of peak pulse intensity for $130 \mathrm{fs}, 267 \mathrm{~nm}$ pulses normalized to an absolute gas pressure of $10^{-7}$ mbar. (a) Xe (black circles), $\mathrm{N}_{2}$ (red squares) and $\mathrm{O}_{2}$ (blue triangles); (b) indole (black circles) and toluene (red squares). Dashed lines show $I^{3 / 2}$ trends, solid lines show (a) $I^{3}$ and (b) $I^{2}$ trends.

Table 1. Cross sections $\left(\mathrm{cm}^{2}\right)$ used to fit the data in Figure 1(b)

\begin{tabular}{|l|l|l|}
\hline & Indole & Toluene \\
\hline Excitation $\sigma_{1}{ }^{51,52}$ & $1.0 \times 10^{-17}$ & $1.3 \times 10^{-18}$ \\
\hline Ionization $\sigma_{2}$ & $2.0 \times 10^{-17}$ & $1.4 \times 10^{-17}$ \\
\hline
\end{tabular}

\section{Discussion}

Let us now consider the laser pulse conditions required for real time detection of an aromatic molecule at a concentration of 1 pptv (part per trillion by volume) in air using REMPI. The ion production rate is given by eqn. 7 multiplied by the laser repetition rate $R$. We make the assumption that a laser beam of full width half maximum $D=2 \mathrm{~mm}$ crosses a gas jet of width 2 $\mathrm{mm}$ and a density of $2 \times 10^{14} \mathrm{~cm}^{-3}$ (such gas target conditions have been achieved previously ${ }^{54}$ ). Using toluene as an exemplar, if an ion production rate of $10 \mathrm{~s}^{-1}$ is required for close to real time detection, then the laser must satisfy the condition

$E^{2} R>0.001$

Therefore, for a laser operating at $1 \mathrm{kHz}$, a pulse energy greater than $1 \mathrm{~mJ}$ is required (or $0.3 \mathrm{~mJ}$ at $10 \mathrm{kHz}$ ). For the gas jet conditions described this corresponds to a limit of detection of a few attomoles.

As eqn. 7 includes the assumption that any dynamics in the intermediate excited state does not alter the ionization probability, there is no dependence on the pulse length. However, this is not the case when we consider the yield of ions from air given by eqn. 6 . If we impose the constraint that the rate of ions generated from $\mathrm{O}_{2}$ and $\mathrm{N}_{2}$ must be no more than $10^{4} \mathrm{~s}^{-1}$ in order to avoid detector saturation, the cross sections obtained in Section III give the following condition

$$
\tau^{2}>10^{-17} E^{3} R
$$

which for a $1 \mathrm{kHz}$ repetition rate, means the pulse length must be greater than $10 \mathrm{ps}$.

These laser conditions are readily satisfied by current solidstate laser systems based on Ti:Sapphire $(800 \mathrm{~nm}), \mathrm{Nd}$ :YAG $(1064 \mathrm{~nm})$ or ytterbium doped crystals $(1028 \mathrm{~nm})$. Assuming $10 \%$ conversion of the fundamental into the $3^{\text {rd }}(266 / 7 \mathrm{~nm})$ or $4^{\text {th }}$ harmonic $(257 \mathrm{~nm})$ respectively, a laser producing $10 \mathrm{~mJ}$, $>10$ ps pulses at $1 \mathrm{kHz}(10 \mathrm{~W})$ would be capable of detecting toluene at the pptv level or sub pptv for indole in real time. While these types of laser systems are still mostly found in research labs, user friendly short pulse fibre and disc laser systems are approaching similar specifications ${ }^{55}$. With further optimization of the laser-gas interaction geometry ${ }^{56}$ which could include multiple reflections of the laser through the target, these detection sensitivities could be reached with current commercial lasers which are compact, rugged, and modestly priced. 


\section{Conclusions}

By measuring the ion yields of several gases irradiated with femtosecond laser pulses at a wavelength of $267 \mathrm{~nm}$, we have measured single and multiphoton ionization cross sections for some exemplar gases. With these values we show that for aromatic organic molecules which are resonant at this wavelength, attomole detection limits can be achieved with ionization rates exceeding that of $\mathrm{N}_{2}$ and $\mathrm{O}_{2}$ sufficiently to facilitate real-time detection in air at 1 pptv concentrations. This could be achieved with currently available $\mathrm{kHz}$ picosecond laser systems producing energies of several $\mathrm{mJ}$ per pulse. As many of the organic molecules have chromophores which absorb in this wavelength range, particularly those of interest for health monitoring, this sensitivity of detection could open up trace detection of new biomarkers in breath, blood and biopsy analysis. As most drugs are also resonant at these wavelengths, there is further potential for applications in pharmacokinetics $^{57}$.

Other organic molecules which absorb more weakly in this wavelength range will naturally require higher concentrations for identification. However, for ketones with excitation cross sections around $5 \times 10^{-20} \mathrm{~cm}^{2}$ at $267 \mathrm{~nm}^{58}$, this would still be an impressive 25 pptv. Alternatively shorter wavelengths available using the next laser harmonic (200, 206 or $213 \mathrm{~nm}$ ) would enable resonant $1+1$ ionization of most organic molecules. For those molecules with excited states which decay on ultrafast timescales, higher limits of detection can also be expected as the ionization is not as efficient. However, this can be mitigated through the use of femtosecond pulses ${ }^{23}$, albeit higher concentration levels would be required since ionization of the background gas will be more efficient.

Ultimately, the ideal laser system would be one which can produce wavelength tuneable picosecond pulses. A 10 ps pulse at $267 \mathrm{~nm}$ can in principal support a bandwidth of $2 \mathrm{~cm}^{-1}(0.01$ $\mathrm{nm}$ ), which can easily resolve vibrational structure in the absorption spectrum. Selection of absorption maxima would enhance the sensitivity, but by scanning the wavelength a two dimensional spectrum (mass vs wavelength) could also be generated. This would be particularly valuable for identifying compounds in very complex mixtures, including isomers ${ }^{5-8}$. Further discrimination in the ionization stage can also be obtained using a two color scheme, as has been demonstrated in nitric oxide ${ }^{19}$.

By using circularly polarized pulses, this selectivity could be extended to identifying enantiomers through circular dichroism in the ion yields as has been demonstrated in some exemplar molecules $59,60,61,62,63$. Although this will be hard to achieve in practice as the circular dichroism is typically very small, the sensitivity would far outstrip conventional chiral detection methods. Given the prevalence of chirality in biological molecules and therapeutic drugs, a chiral-REMPI analysis instrument would be a powerful analytical tool.

In conclusion, with the rapid advances in laser technology, the opportunity for more widespread use of short pulse lasers combined with mass spectrometry for very high sensitivity trace analysis is becoming possible, particularly for health related applications. While the use of such lasers in bed-side monitoring devices is unlikely, there is potential for off-line analysis of breath, fluid or tissue samples which would offer much higher sensitivity than any other currently available analytical techniques.

\section{Acknowledgements}

This work was supported by the STFC Laser Loan Scheme, the Leverhulme Trust (grant RPG-2012-735), the UK's Engineering and Physical Sciences Reseach Council (grant EP/M001644/1). GA is supported by EPSRC's Doctoral Training Grant scheme, JM by the Northern Ireland Department of Employment and Learning. The participation of TJK and JTC was made possible by Science Foundation Ireland Grant No. 12/IA/1742.

\section{Notes and references}

a Centre for Plasma Physics, School of Maths and Physics, Queen's University Belfast, BT7 1NN, UK

${ }^{b}$ School of Physical Sciences and National Centre for Plasma Science \& Technology, Dublin City University, Dublin 9, Ireland

*Email: j.greenwood@qub.ac.uk.

${ }^{1}$ U. Boesl, H. J. Neusser, E.W. Schlag, Z. Naturforsch. 1978, A33, $1546-1548$

${ }^{2}$ L. Zandee, R. B. Bernstein, J. Chem. Phys., 1979, 71, 1359-1371

${ }^{3}$ U. Boesl, H. J. Neusser, E.W. Schlag, Chem. Phys. 1981, 55, 193204

${ }^{4}$ U. Boesl, J. Mass Spectrom. 2000, 35, 289-304

${ }^{5}$ L. Oudejans, A. Tuati, B. K. Gullett, Anal. Chem. 2004, 76, $2517-$ 2524

${ }^{6}$ H. Oser, R. Thanner, H.-H. Grotheer, Chemosphere, 1998, 31, 2361-2374

${ }^{7}$ M. Nomayo, R. Thanner, H.-H. Grotheer, Appl. Phys. B 2000, 71, 681-687

${ }^{8}$ H. Tsukatani, H. Okudaira, T. Uchimura, T. Imasaka, Anal. Sci. 2009, 25, 599

${ }^{9}$ B. K. Gullett, L. Oudejans, D. Tabor, A. Touati, S. Ryan, Environ. Sci. Technol. 2012, 46, 923-928

${ }^{10}$ R. Zimmermann, H. J. Heger, A. Kettrup, U. Nikolai, Fres. J. Anal. Chem. 2000, 366, 368-374

${ }^{11}$ B. K. Gullett, A. Touati, L. Oudejans, Atmos. Environ. 2008, 42, 2117-2128

${ }^{12}$ T. Streibel, R. Zimmerman, Annu. Rev. Anal. Chem. 2014, 7, 361381 
${ }^{13}$ M. Nomayo, R. Thanner, H.-H. Grotheer, Appl. Phys. B 2000, 71, 681-687

14 S. Schmidt, M. F. Appel, R. M. Garnica, R. N. Schindler, T. Benter, Anal. Chem. 1999, 71, 3721-3729

${ }^{15}$ T. Streibel, K. Hafner, F. Mühlberger, T. Adam, RZimmermann, Appl. Spect. 2006, 60, 72-79

${ }^{16}$ R. Thanner, H. Oser, H.-H. Grotheer, Eur. Mass Spectrom. 1998, 4, 215-222

17 Y. Deguchi, S. Dobashi, N. Fukuda, K. Shinoda, M. Morita, Environ. Sci. Technol. 2003, 37, 4737-4742

${ }^{18}$ T. Uchimura, T. Imasaka, Anal. Chem. 2000, 72, 2648-2652

${ }^{19}$ L. C. Short, R. Frey, T. Benter, Appl. Spect. 2006, 60, 217-222

${ }^{20}$ H. Oser, S. E. Young, M. J. Coggiola, Breath Analysis Using Photoionization Mass Spectrometry. 2004, SRI International Menlo Park, CA, USA.

${ }^{21}$ A. Li, T. Uchimura, H. Tsukatani, T. Imasaka, Anal. Sci. 2010, 26, 841-846

${ }^{22}$ A. Li, J. Song, Y. Sun, T. Jiao, J. Spect. 2014, 134828

23 S. Yamaguchi, T. Uchimura, T. Imasaka, Anal. Sci. 2006, 22, 1483-1487

${ }^{24}$ Y. Watanabe-Ezoe, X. Li, T. Imasaka, T. Uchimura, T. Imasaka, Anal. Chem. 2010, 82, 6519-6525

${ }^{25}$ Y-.C. Chang, T. Imasaka, Anal. Chem. 2013, 85, 349-354

${ }^{26}$ R. Weinkauf, P. Aicher, G. Wesley, J. Grotemeyer, E. W. Schlag, J. Phys. Chem. 1994, 98, 8381-8391

${ }^{27}$ Y. Hashiguchi, S. Zaitsu, T. Imasaka, Anal. Bioanal. Chem. 2013, 405, 7053-7059

${ }^{28}$ K. W. D. Ledingham, R. P. Singhal, Int. J. Mass Spectrom. Ion Proc. 1997, 163, 149-168

${ }^{29}$ J. Peng, N. Puskas, P. B. Corkum, D. M. Rayner, L.V. Loboda, Anal. Chem. 2012, 84, 5633-5640

${ }^{30}$ O. Kelly, M. J. Duffy, R. B. King, L. Belshaw, I. D. Williams, J. Sá, C. R. Calvert, J. B.Greenwood, Analyst 2012, 137, 64

${ }^{31}$ M. Liu, C. Wu, Z. Wu, H. Yang, Q. Gong, W. Huang, T. Zhub, J. Am. Soc. Mass Spectrom. 2010, 21, 1122-1128

${ }^{32}$ S. M. Hankin, D. M. Villeneuve, P. B. Corkum, D. M. Rayner, Phys. Rev. Lett. 2000, 84, 5082-5085

33 J. Muth-Böhm, A. Becker, F. H. M. Faisal, Phys. Rev. Lett. 2000, 85, 2280-2283

${ }^{34}$ A. Jaroń-Becker, A. Becker, Laser Phys., 2009, 19, 1705-1711

${ }^{35} 0$ A. E. Boguslavskiy, J. Mikosch, A. Gijsbertsen, M. Spanner, S. Patchkovskii, N. Gador, M. J. J. Vrakking, A. Stolow, Science 2012, 335, 1336-1340

36 A. Kucher, A. Wucher, N. Winograd, J. Phys. Chem. C, 2014, 118, 25534-25544

${ }^{37}$ M. A. Turner, S. Bandelow, L. Edwards, P. Patel, H. J. Martin, I. D. Wilson, C. L. P. Thomas, J. Breath Res. 2013, 7, 017102

${ }^{38}$ D. Poli, P. Carbognani, M. Corradi, M. Goldoni, O. Acampa, B. Balbi, L. Bianchi, M. Rusca, A. Mutti, Resp. Res. 2005, 6, 71

${ }^{39}$ S. Kischkel, W. Miekisch, A. Sawacki, E.M. Straker, P. Trefz, A. Amann, J.K. Schubert, Clin. Chim. Acta 2010, 411, 1637-1644
${ }^{40}$ J.D. Alexander, L. Graham, C. R. Calvert, O. Kelly, R.B. King, I. D. Williams, J. B. Greenwood, Meas. Sci. Technol., 2010, 21, 045802

${ }^{41}$ Y. Itikawa, J. Phys. Chem. Ref. Data, 2006, 35, 31-53

42 J. R. Vacher, F. Jorand, N. Blin-Simiand, S. Pasquiers, Chem. Phys. Lett., 2007, 434, 188-193

${ }^{43}$ B. Trost, J. Stutz, U. Platt, Atmos. Environ. 1997, 31, 3999-4008

${ }^{44}$ T. Etzkorn, B. Klotz, S. Sörensen, I. V. Patroescu, I. Barnes, K. H. Becker, U. Platt, Atmos. Environ. 1999, 33, 525-540

${ }^{45}$ P. Sahay, S. T. Scherrer, C. Wang, Sensors 2013, 13, 8170-8187

${ }^{46}$ M. Yujing, A. Mellouki, J. Photochem. Photobio. A, 2000, 134, $31-36$

${ }^{47}$ S. Fally, M. Carleer, A. C. Vandaele, J. Quant. Spect. Rad. Trans. 2009, 110, 766-782

${ }^{48}$ K. C. Kulander, Phys. Rev. A 1988, 38, 778-787

${ }^{49}$ E. J. McGuire, Phys. Rev. A 1981, 24, 835

${ }^{50}$ R.S. Mangina, J.M. Ajello, R.A. West, D. Dziczek, ApJ 2011, 196, $1-34$

${ }^{51}$ T. Etzkorn et al. Atmospheric Environment 1999, 33, 525

52 J.E. Bartmess, J.F. Liebman, J.L. Holmes, R.D. Levin, W.G. Mallard, "Ion Energetics Data" in NIST Chemistry WebBook, NIST Standard Reference Database Number 69, Eds. P.J. Linstrom and W.G. Mallard, National Institute of Standards and Technology, Gaithersburg MD, 20899, http://webbook.nist.gov, (retrieved January 15, 2015)

${ }^{53}$ E. H. Strickland, J. Horwitz, C. Billups, Biochem. 1970, 9, 49144921

${ }^{54}$ M.F. Appel, L.C. Short, T. Benter, J. Am. Soc. Mass Spectrom. 2004, 15, 1885-1896

${ }^{55}$ Z. Yang, X. Hu, Y. Wang, W. Zhang, W. Zhao, Chin. Opt. Lett., 2011, 9, 041401

${ }^{56}$ T. Matsui, T. Imasaka, Anal. Sci. 2014, 30, 445-449

57 J. Kleeblatt, S. Ehlert, J. Hölzer, M. Sklorz, J. Rittgen, P. Baumgärtel, J.K. Schubert, R. Zimmermann, Appl. Spect. 2013, 67, 860-872

${ }^{58}$ M. Yujing, A. Mellouki, Anal. Chim. Acta, 2011, 694, 108-114

${ }^{59}$ C. Loge, A. Bornschlegl, and U. Boesl, Anal Bioanal Chem. 2009, 395, 1631

${ }^{60}$ P. Horsch, G. Ubasch, and K-M. Weitzel, Chirality, 2012, 24, 68

${ }^{61}$ U. Boesl, A. Bornschlegl, C. Logé, K. Titze, Anal Bioanal Chem, 2013, 405, 6913

${ }^{62}$ A. Hong, C. M. Choi, H. J. Eun, C. Jeong, J. Heo, N. J. Kim, Angew. Chem. Int. Ed., 2014, 53, $7805-7808$

${ }^{63}$ K. Titze, T. Zollitsch, U. Heiz, and U. Boesl, ChemPhysChem, $2014, \mathbf{1 5}, 2762-2767$ 